\title{
Through the Looking Glass: Metacognitive Reading Strategies in Open Distance Learning
}

\author{
Dr Jennifer J. Roberts \\ University of South Africa \\ E-mail: buckjj@unisa.ac.za \\ Professor lgnatius G. P. Gous \\ University of South Africa \\ E-mail: gousigp@unisa.ac.za
}

Doi:10.5901/jesr.2014.v4n3p283

\begin{abstract}
This paper firstly describes the cognitive processes involved in acts of reading and the importance thereof in an Open Distance Learning $(O D L)$ environment. Due to the fact that reading is a very recent development in terms of human history, there is no dedicated or inborn cognitive ability devoted to reading. Reading is a complex cognitive activity, drawing upon several more basic neural networks such as vision, speech, sensory experiences and motor activity. The question is also asked whether onscreen reading is going to replace paper-based reading. Is the former going to replace the latter? If so, what are the implications for teaching, especially in an ODL setting? If not, what will be delivered on paper, what will be made available online, and what will overlap or be "hybrid vehicles"? In other words - what should be only in paper, what should only be onscreen, and what should be available in both formats? Whatever the answers to the above questions might turn out to be, one thing is clear and that is that all students, whether they read on paper or online and onscreen, need to be taught metacognitive reading strategies. Many students whether they are still in school or at university, or simply life-long learners, are poor readers and lack effective reading strategies. This paper therefore indicates that we need to teach our students not only the course content, but also strategies to read effectively in order to master the course content while reading. Therefore we have to teach students how to read the course content we present to them, whether it is on paper, on- screen or on both. If not, we will have to live with the reality of many shattered dreams and crumpled futures.
\end{abstract}

Keywords: Reading; the teaching of reading; metacognition; distance education; digital natives; ODL; ODeL; Stanislas Dehaene

\section{Introduction: Looking Through the Glass}

In a YouTube video (http://www.youtube.com/watch?v=aXV-yaFmQNk) that has gone viral, a one year old "digital native" first swipes an iPad screen, and then attempts to do the same with the pages of a magazine. When the magazine pages do not respond the way the iPad did, she tests her finger against her leg to see if her finger is still "working".

Does it mean that people who grew up with computers - sometimes called digital natives - are natural readers on glass, not only preferring on-screen reading to paper reading, but are also more successful at it? More ODL institutions are becoming almost exclusively digital in their means of tuition and even assessment. This implies they actually force their ODL students into becoming digital readers, accessing and studying their course material on-screen. Are ODL students ready for it? Are some students prepared (the digital natives), while others (BC or Before Computer students) are not? What about the ODL lecturers and members of faculty who are mostly of the BC-variety? Do they still almost secretly do it between the covers, while being forced by their institutions and developments to do it online and onscreen? Is this a case of a house being divided onto itself, or an instance of "tuitional schizophrenia"?

As part of a series of articles on metaskills in education such as listening, reading, writing and studying, this article is an overview on reading in education, scouting the terrain and identifying issues. Subsequent articles will focus on specific issues, ranging from literature reviews, quantitative and qualitative research, the teaching of reading and reading in ODL.

For now the question is "Do we understand reading in education and distance education?" 


\section{Reading in an ODL Context}

This article investigates the meta-skill of reading in a distance education environment. The theoretical framework for this study is based on the classification of distance education into different generations based on technological as well as pedagogical constructs, as suggested by Taylor (2001) and Anderson and Dron (2011). Anderson and Dron (2011, 80) state "It is clear that whether the learner is at the centre or part of a learning community or learning network, learning effectiveness can be greatly enhanced by applying, at a detailed level, an understanding of how people can learn more effectively: Cognitive, behaviourist, constructivist and connectivist theories each play an important role."

Reading has always the backbone of ODL tuition, and will always be. This can be seen from Table 1 which is based on Taylor's five generations of distance education theory.

The following table provides an overview Taylor's theory on 'the generations of distance education. (Adapted from Hedenrych \& Prinsloo, 2010:8-9):

Table 1: Five generations of distance education

\begin{tabular}{|l|l|}
\hline & Taylor (1999 and 2001) \\
\hline 1st & Correspondence - single medium (print) - mass production of content \\
\hline 2nd & Teleconferencing - audio - communications network - synchronous \\
\hline 3rd & Multi-media and computer-assisted learning - interaction with content \\
\hline 4th & Flexible learning via online delivery - communication enhanced online \\
\hline 5th & Intelligent flexible learning - automated content and responses and campus portals \\
\hline
\end{tabular}

As can be seen from Table 1, reading has always been at the forefront of teaching and learning and particularly in the case of distance education which has its very foundation on the so called $1^{\text {st }}$ generation of correspondence education.

Moore $(2007,91)$ states that ODL is characterised by the distance that exists between educator, learner and institution, which he calls the transactional distance. He describes transactional distance as "the space where instructors and learners accomplish the work of learning in an environment that separates actors in both time and geographic distance", and also "the interplay of teachers and learners in environments that have the special characteristic of being spatially separate from one another". This situation creates a cognitive space between educator and learner, "a psychological and communications gap, a space of potential misunderstanding between the inputs of instructor and those of the learner".

One way to empower students is to focus on learning strategies which can be defined as thoughts and behaviors intended to influence the learner's ability to select, acquire, organize, and integrate new knowledge (Weinstein \& Mayer, 1986). Learning strategies are designed to teach learners how to learn (Jonassen, 1985). Effective learning involves knowing when to use a specific strategy, how to access that particular strategy, as well as when to abandon an ineffective strategy (Jones, Sullivan, Palincsar, Sederburg Olge, \& Glynn Carr, 1987). McKeachie, Pintrich, Lin \& Smith (1986) incorporated elements of several learning models, including the cognitive approach established by Weinstein and Mayer (1986), into a taxonomy of learning strategies. The taxonomy proposed by McKeachie and others encompasses the cognitive, metacognitive, and resource management aspects of learning (Table 1).

Table 2. Taxonomy of Learning Strategies

\begin{tabular}{|l|l|}
\hline 1. Cognitive Strategies & Rehearsal strategies \\
\hline & Elaboration strategies \\
\hline 2. Metacognitive strategies & Organisational strategies \\
\hline & Planning strategies \\
\hline & Monitoring strategies \\
\hline 3. Resource management strategies & Regulating strategies \\
\hline & Time management \\
\hline & Study environment \\
\hline & Effort management \\
\hline
\end{tabular}

(Adapted from Filcher \& Miller, 2000) 
According to McKeachie et al. (1986) and Weinstein and Mayer (1986), cognitive strategies are important for understanding how information is processed and encoded in a learning environment, while metacognitive strategies allow a student to monitor his/her performance through planning, monitoring, and self-regulation. Resource management strategies assist the student in managing the learning environment and available resources (McKeachie et al., 1986). McKeachie et al.'s (1986) taxonomy is a clear, concise, and comprehensive model that identifies general learning strategies and specific learning tactics that may be examined in a distance education environment. The cognitive component of McKeachie's taxonomy focuses on the methods by which students actively process information and structure this information into memory (Weinstein \& Mayer, 1986). In this regard, reading skills are examined in this article. Reading and comprehension skills are required in all three learning processes proposed by McKeatchie et al (1996) i.e. cognitive strategies, which include rehearsal, elaboration, and organization, rehearsal strategies which are employed by learners to remember material using repetition (Olgren, 1998) and in elaboration by which the learner builds an internal connection between what is being learned and previous knowledge.

According to Dreyer and Nel (2003), research conducted in South Africa indicates that many South African students who register for undergraduate study each year are under-prepared for university education and that many of these students also have low levels of reading ability. This has an adverse effect on their chances of academic success. In order to meet the reading needs of students in the 21st century, educators are pressed to develop effective instructional means for teaching reading comprehension and reading strategy use.

They go on further to state that one of the most serious problems in higher education, but one which is often not recognized by either students or lecturers until some way into academic courses, is the problem of reading, perhaps because reading per se is not assessed. However, the results or outputs from reading are what is being assessed.

It is the contention of the authors that the poor quality of reading and comprehension skills, particularly in the South African context, is partly responsible for the low rate of academic success among distance education students.

Reading has always been the backbone of ODL tuition, and it will always be so. As is, students are often poor readers of printed material. However, there is a shift, even a revolution in the offing as we move through the generations of distance education. Reading is shifting from paper to glass. Are educators, students and institutions ready for this? Do we know what is coming?

Distance education (DE) and ODL institutions are faced with several complex realities when it comes to reading.

(1) Reading proficiency varies markedly - from excellent to poor.

(2) Readers vary markedly - from "old school" readers on paper to digital natives or "screenagers" reading on screen.

(3) Readers often have to read in languages other than their mother tongue, adding to difficulty in reading

(4) Reading technology differs - from reading on paper to reading on glass or screen.

(5) The strategies for reading on paper differ from strategies for reading on glass.

(6) Research is moving into the digital domain, with students reading what is available online and onscreen.

(7) The teaching of reading is necessary, but it is not happening.

(8) Institutional policy is beginning to force students to read on glass.

It is clear that reading as such is an issue, and reading online is even more so.

Institutions should be aware of reading weaknesses, and make contingency plans. Lecturers should be aware of it, and include relevant reading tuition in course content delivery - providing what is to be studied as well as suggesting how to study it. Students should be aware of reading as an indispensable skill that should be mastered and used.

Surveying the issues, the rest of the article will touch upon reading as deciphering, reading as attribution of meaning, the difference of reading on paper and reading on glass, metacognitive reading strategies, and suggestions for future research.

\section{Reading - Deciphered}

Due to the fact that reading is a very recent development in terms of human history, there is no dedicated or inborn cognitive ability devoted to reading. Reading is a complex cognitive activity, drawing upon several more basic neural networks such as vision, speech, sensory experiences and motor activity.

Speaking and hearing are inborn abilities which developed in humns over millennia, and human brains are hardwired for that. Since ancient times teaching and learning has been conducted by means of speaking and listening. Even today, informal tuition in families and communities is still mainly oral. The proliferation of knowledge and the need for long term storage called for more than minds and vocal chords, and reading and writing started to fulfill the need. 
In evolutionary terms, however, reading is a very recent and young human ability, with writing only having been developed over the past 4000 years. Reading enabled the storage and transmission of vast volumes of information, much more than possible in a few minds and transmitted by a few mouths. In this sense reading superseded speaking and hearing in consequence, especially in formal teaching and learning.

Not being an inborn ability, and with no hardwired systems in the brain devoted to reading, the question is how do humans manage to read?

Dehaene (2009), a neuroscientist, proposed the theory of neuronal recycling to explain the human ability to read. What is hardwired into human brains is the ability to see, and by seeing, to navigate terrain. When learning to read, these systems in the brain are used, and by using it changed to the ability to read. All writing symbols, whether pictographic or orthographic, utilise shapes known from the environment, such as the interchanging lines in $T, L, X$ and *. Dehaene used fMRI scans to pinpoint the areas where reading takes place. He then compared the brains of literate and illiterate 50 year olds, and was able to describe the differences in brain anatomy between the two groups.

It has always been known that reading should be taught from a young age, and Dehaene's research explains and confirms why this is the case. Reading needs to re-train certain neuronal systems, and also needs to link these changed systems to other areas pertinent to reading, such as areas involved in sound and language. Brain plasticity is high when babies are still young, and early exposure to reading-related skills activates and eventually changes the areas pertinent to reading.

According to Wolf (2007) every reader has to read from scratch. Teaching reading begins at a very young age by being read to. This stimulates all the necessary building blocks such as the child's basic language skills, sentence order, and listening to word sounds and phonemes. It also stimulates vocabulary and the beginning to see things from someone else's perspective. In this way we help children to learn the sounds of a language, as well as to understand that writing systems represents spoken language. Added to this is the understanding of words and sentences and how they fit together. They might also begin to understand that there are different languages if they are in a multi-lingual environment.

When this process is lacking, as is often the case in areas of poverty and poor schooling, it becomes understandable why learners read poorly. Parents are not proficient readers, they do not read to their children, they do not have access to books, and children are not stimulated by having access to good pre-school facilities. With a bad start children will stay behind if there are not remedial steps taken. If these children do make it through school, they will arrive at university still lacking good reading skills. Remedial steps are indispensable for poor readers of all ages.

\section{Reading - Understood}

Automaticity and fluency in reading is a prerequisite for understanding the meaning of what is being read, as well as for the creation of meaning from what is being read. When people struggle to decipher, they focus on that to such an extent that they do not remember the content of what they have read.

According to Wolf (2007), readers go through several stages. If all goes well, pre-readers become novice readers with phoneme awareness and able to put the sounds and the letters together as they read. The next stage is the decoding reader, being able to recognise words, prefixes and suffixes, and moving towards comprehension. In this stage metacognitive reading skills begin to emerge, such as making inferences, prediction and thinking ahead. The final stage is the fluent comprehending reader. With fluency comes the ability to think about what is being read. It is also the stage when awareness of deeper meaning begins to develop.

Fluent comprehension requires explicit instruction and a desire to read. The realities in many schools and communities are that explicit instruction does not take place, and many children are stuck in the deciphering phase. Struggling readers do not develop a desire to read, leading to a vicious circle.

The implications for DE and ODL institutions are significant. To remedy situations that originate in early childhood is difficult. All is not lost however, as is indicated through the interventions by Dreyer and Nel (2003) referred to earlier. What should be considered carefully is the format and practicalities of interventions. Poor readers might not be motivated to participate in remedial programs. ODL and DE students are often employed or studying part time. In such cases time is of a premium, and taking extra classes which they might perceive as non-core activities will further erode motivation to participate in remedial programs.

What should be considered is to include reading instruction in the way the course content is presented, delivered and assessed. In this way reading is being modeled, and reading instruction is made relevant to the mastery of content. Focused and subject specific reading instruction can be given in terms of the reading strategies such as when to use 
skimming, scanning and in-depth reading, as well as how to alternate between critical, task-oriented, relational and analytical reading (see discussion of listening style - Bodie, Worthington \& Gearhart, 2013, Roberts \& Gous, 2014)

\section{Reading - From Tablet to Tablet}

To many students reading on paper is not easy. Moving to reading on screen might prove even more difficult. The question is also asked whether on-screen reading is going to replace paper-based reading. Is the former going to replace the latter? If so, what are the implications for teaching, especially in an ODL setting? If not, what will be delivered on paper, what will be made available online, and what will overlap or be "hybrid vehicles"? In other words - what should be only in paper, what should only be onscreen, and what should be available in both formats?

The process of deciphering texts is basically the same, whether it happens on paper or on screen. However, there are aspects of the respective media which make them very dissimilar to such an extent that researchers consider the possibility that on-screen reading might actually change the brain in ways different from reading on paper (Killian 2009).

The most important difference is referred to as digital distraction. Online reading is disorganised, chaotic and linked. It is easy to follow link to link, never returning to the original source. The British Library and JISC commissioned a report called Researchers of Tomorrow. The report focused on the information-seeking and research behaviour of doctoral students in 'Generation Y', born between 1982 and 1994 and not 'digital natives', and found that distractions inherent in using the internet and social media emerged as an acknowledged problem (Education for Change 2012, 32).

Wolf's (2007) book on the story and science of the reading brain is titled Proust and the Squid. With Proust she refers to the deep changes that can result from immersion in a book and from reading. The squid has been studied in cognitive science because if the brain is not wired correctly, the squid cannot swim. Wolf (2007) is concerned that reading on screen might impede the brain's ability to assimilate and later access information.

Institutional decisions to move to on-screen reading, whether partially or exclusively, will have significant consequences. The issue is not merely a question of access to technology. More importantly is the issue whether students, both "digital immigrants" and "digital natives", are prepared to cope with on-screen reading, especially with the digital distractions which is inherent in onscreen reading. Proper training how to manage onscreen reading is necessary.

\section{Teaching Metacognitive Reading Skills}

Reading skills needs to be taught. Stand-alone courses are good in the sense tht they can be comprehensive and professional. Because of time constraints, and motivational factors, not all students will make use of it. Reading strategies should be included and be made an inherent part of the course content and assessment. For this reason educators should be informed about the importance of teaching reading, and trained how to incorporate it in their courses.

Assesment should also be conducted in ways that reflect the training. Herewith is a list of metacognitive strategies that can be used in teaching and assessing learners.

Strategies and descriptions:

- Goal setting: Set goal, monitor movement towards goal.

- Skim reading: Get idea and overview by reading titles, headings, look at pictures and illustrations.

- Schema Activation: Activate background knowledge about subject, author, genre and stgructure of text.

- Prediction: Make predictions about what is going to happen / written, test assumptions.

- Monitor own understanding: Monitor whether on right track. Make sure of understanding of terms and phrases.

- Pose Questions: Ask questions about content and author's intentions

- Visualise: Pictures in the mind.

- Look back, reread and amend: Continuous reflection for the sake of the creation of meaning.

- Make deductions: Link ideas in text with personal experiences, knowledge of other texts, general knowledge.

- Make links: Link ideas in text with existing knowledge.

- Sum up and make conclusions: Identify main idea or core ideas.

- Evaluate: Approach texts according to their nature - factual, inspirational, etc.

- Sinthesise: Link all aspects.

What is clear is that all students and for that matter all readers - whether they read on paper or online and onscreen, need to be taught meta-cognitive reading strategies. Many students, whether they are still in school or at 
university, or simply life-long learners, are poor readers and lack effective reading strategies.

Some metacognitive reading strategies are universal to reading irrespective of the medium, while others are medium-specific. We need to teach our students not only the course content, but also strategies to read effectively in order to master the course content while reading.

\section{Conclusion and Future Research}

What is needed is thorough research on the issue of reading, but also swift action. Research should be carried on the skills and the habits of actual readers, ranging from the successful to the struggling, the young and the old, male and female, in order to set benchmarks. Reading in a second language should be focussed upon, the measuring scales that are available, and whether it possible to develop an inhouse scale.

We have to teach students how to read the course content we present to them, whether it is on paper, on-screen or on both. If not, we will have to live with the reality of many shattered dreams and crumpled futures.

Do you read me?

\section{References}

Anderson, T. \& Dron, J. (2011). Three generations of distance education pedagogy. International review of research in open and distance learning. Vol 12(3), 80-97.

Bodie, G. D., Worthington, D. L. \& Gearhart, C. C. (2013). The Listening Styles Profile-Revised (LSP-R): A Scale Revision and Evidence for Validity, Communication Quarterly, 61:1, 72-90.

Dehaene, S. (2009). Reading in the brain: the new science of how we read. New York: Penguin.

Dreyer, C. \& Nel, C. (2003) Teaching reading strategies and reading comprehension within a technology-enhanced learning environment.System 31 (2003) 349-365.

Education for Change. (2012). Researchers of Tomorrow. The research behaviour of Genertion Y doctoral students. JISC and British Library, http://www.jisc.ac.uk/publications/reports/2012/researchers-of-tomorrow.aspx\#menu.

Filcher, C. \& Miller, G. (2000). Learning strategies for distance education students. Journal of agricultural education Vol.41(1), 62-68.

Heydenrych, J.F. \& Prinsloo, P. (2010). Revisiting the five generations of distance education. Progressio 32 (1), 5-26.

Jonassen, D.H. (1985). Learning strategies: A new educational technology. Programmed Learning and Educational Technology, 22(1), 26-34.

Jones, B.F., Sullivan Palincsar, A., Sederburg, Olge, D., \& Glynn Carr, E. (Eds.). (1987). Strategic teaching and learning: Cognitive instruction in the content areas. Alexandria, VA: Association for Supervision and Curriculum Development.

McKeachie, W. J., Pintrich, P.R., Lin, Y., \& Smith, D. (1986). Teaching and learning in the college classroom: A review of the research literature. In Ann Arbor, MI: National Center for Research to Improve Postsecondary Teaching and Learning, University of Michigan.

Killian, L. (2009). New textual formats: reading online is re-wiring the human brain and changing how we process information. Dalhousie Journal for Interdisciplinary Management 4.

Moore, M.G. (2007). The Theory of Transactional Distance. In M.G.Moore (Ed.) (2007). The handbook of distance education. Second Edition.Mahwah, N.J. Lawrence Erlbaum Associates. pp. 89-108.

Olgren, C.H. (1998). Improving learning outcomes: the effects of learning strategies and motivation. In C. Campbell Gibson (Ed.), Distance learners in higher education: Institutional response for qualitve outcomes (pp. 77-96). Madison, WI: Atwood Publishing.

Roberts, J. J.\& Gous, I. G. P. (2014). ODEL - Open and Distance Education and Listening: The Need for Metacognitive Listening Strategies. JSER 4,2.

Taylor, J.C. (2001). Fifth generation distance education. Higher education series 40.June. Australia: Department of Education, Training and Youth Affairs.

Weinstein, C.E., \& Mayer, R.E. (1986). The teaching of learning strategies. In M.Wittrock (Ed.), Handbook of research on teaching. (pp. 315-327). New York: Macmillan.

Wolf, M. (2007). Proust and the squid: The story and science of the reading brain. New York: HarperCollins.

YouTube. http://www.youtube.com/watch?v=aXV-yaFmQNk_. Accessed 1 July 2013. 